\title{
ANALISIS STRATEGI PENINGKATAN DAYA SAING SD ISLAM AL-SYUKRO UNIVERSAL DALAM MENGHADAPI PENGUATAN DAYA SAING DI TAHUN 2017
}

\author{
Khotimatus Sadiyah \\ email : diyah.khotimatus@gmail.com
}

\begin{abstract}
ABSTRAK
Penelitian ini bertujuan untuk mendapatkan informasi tentang posisi dan kondisi SD islam Al-Syukro Universal dalam bersaing serta mengetahui strategi yang lebih baik dalam meningkatkan daya saingnya. Penelitian dilakukan dengan menggunakan metode deskriptif kualitatif.Adapun responden dalam penelitian ini adalah pihak-pihak yang terkait dalam penelitian yang meliputi kepala sekolah, bagian kesiswaan, kurikulum, manajer keuangan, orang tua dan peneliti. Adapun analisis yang digunakan dengan menggunakan analisis SWOT dengan hasil penelitian dapat disimpulkan sebagai berikut: (1) Pada kondisi lingkungan internal internal (IFAS) dengan indikator kekuatan (strength) sebesar 3,54 dikurangi dengan indikator kelemahan (weakness) -2,23 menjadi grand total sebesar 1,31 bernilai posistif. Pada aspek eksternal (EFAS) dengan rincian indikator peluang (opportunity) sebesar 3,66 dikurangi dengan indikator ancaman (threath) yaitu 2,31 menjadi grand total sebesar 1,35 bernilai positif. Kedua kondisi baik internal maupun ekternal keduanya bernialai positif yang berarti bahwa posisi SD Al-Syukro Universal dalam persaingan bisnisnya berada pada kondisi prospektif (kuadran I) dari Matrik kondisi. Hal ini berarti organisasi berada pada posisi yang baik untuk menggunakan kekuatan internalnya guna memanfaatkan peluang eksternal, mengatasi kelemahan internal, dan menghindari ancaman eksternal. (2) Hasil dari scoring analisa SWOT menggambarkan bahwa posisi perusahaan berada pada kuadran I (Prospektif) yang berarti strategi yang dijalankan adalah dengan menggunakan Strategi S-O(StrengthOpportunity) yaitu:mengoptimalkan program pemasaran secara langsung dan tidak langsung, menjaga kualitas program pendidikan, mengoptimalkan jaringan networking dalam pemasaran, dan berperan aktif dalam keikutsertaan sekolah pada kegiatan dinas pendidikan.
\end{abstract}

Kata kunci : Manajemen Strategi, Strategi Bersaing

\begin{abstract}
This study aims to get information about the position and condition of SD Islam Al-Syukro Universal in competing and knowing better strategy in improving it competitivenes. The research was conducted by using qualitative descriptive methode. The respondents in this study are the parties involved in the study covering principals, student affairs, curriculum, financial managers, parents and researchers. The analysis used by using SWOT analysis with the research result can be concluded as follows: (1) In internal internal environment condition (IFAS) with strength indicator (strength) equal to 3,54 minus indicator weakness $-2,23$ become grand a total of 1.31 is posistive. On the external aspect (EFAS) with details of the opportunity indicator of 3.66 minus the threat indicator ie -2.31 to a grand total of 1.35 is positive. Both internal and external conditions are both positive, which means that SD Al-Syukro Universal's position in business competition is in prospective condition (quadrant I) of Matrix condition. This means the organization is in a good position to use its internal strengths to take advantage of external opportunities, overcome internal weaknesses, and avoid external threats. (2) The result of scoring SWOT analysis illustrates that the company position is in quadrant I (Prospective) which means the strategy is run by using SO Strategy (Strength-Opportunity) that is: optimize marketing program directly and indirectly, maintain the quality of education program, optimize networking network in marketing, and take an active role in school participation in education service activities.
\end{abstract}


Keywords: Strategic management, Competitive strategy

\section{A. Pendahuluan.}

Kota Tangerang Selatan (Tangsel) yang secara geografis terletak $30 \mathrm{~km}$ sebelah barat Jakarta dan $90 \mathrm{~km}$ sebelah tenggara Serang, yang merupakan hasil pemekaran dari Kabupaten Tangerang merupakan salah satu kota yang sedang berkembang di Indonesia. Berdasarkan Undang-Undang Republik Indonesia Nomor 51 Tahun 2008 tentang pembentukan kota Tangerang Selatan, kota ini terbagi atas tujuh cakupan wilayah kecamatan diantaranya adalah kecamatan pondok aren, kecamatan serpong utara, kecamatan setu, kecamatan pamulang, kecamatan serpong, kecamatan ciputat dan ciputat timur. Daerahdaerah di kota Tangerang Selatan yang sedang berkembang memiliki berbagai sarana pendidikan dari mulai taman kanak-kanak sampai pada perguruan tinggi. Kualitas dari pendidikan pun juga sangat bervariasi dari gedung mewah ber-AC sampai yang sederhana. Berdasarkan data refrensi Kementrian Pendidikan dan Kebudayaan, tercatat jumlah satuan pendidikan (sekolah per kabupaten/kota) di Tangerang Selatan dari tingkat Sekolah Dasar hingga SMA sederajat berjumlah 1.592 meliputi kecamatan ciputat, ciputat timur, pamulang, pondok aren, serpong utara dan setu.

Tabel 1 Data Jumlah Sekolah di Tangerang Selatan

\begin{tabular}{|c|c|c|c|c|c|c|c|c|c|c|c|c|c|c|}
\hline \multirow[t]{2}{*}{ No } & \multirow{2}{*}{ Kecamatan } & \multicolumn{3}{|c|}{$\mathrm{SD} / \mathrm{MI}$} & \multicolumn{3}{|c|}{ SMP/MTS } & \multicolumn{3}{|c|}{ SMA/MA } & \multicolumn{3}{|c|}{ SMK } & \multirow{2}{*}{ Total } \\
\hline & & $\mathrm{N}$ & $S$ & $\mathrm{Jml}$ & $\mathrm{N}$ & $\mathrm{S}$ & $\mathrm{Jml}$ & $\mathrm{N}$ & $\mathrm{S}$ & $\mathrm{Jml}$ & $\mathrm{N}$ & $\mathrm{S}$ & $\mathrm{Jml}$ & \\
\hline & TOTAL & 159 & 236 & 395 & 23 & 203 & 226 & 14 & 81 & 95 & 7 & 73 & 80 & 796 \\
\hline 1 & Ciputat & 28 & 38 & 66 & 1 & 35 & 36 & 4 & 8 & 12 & 1 & 17 & 18 & 132 \\
\hline 2 & & 19 & 21 & 40 & 4 & 16 & 20 & 2 & 6 & 8 & 1 & 15 & 16 & 84 \\
\hline 3 & Pamulang & 28 & 53 & 81 & 6 & 43 & 49 & 2 & 16 & 18 & 0 & 11 & 11 & 159 \\
\hline 4 & Pondok Aren & 35 & 62 & 97 & 4 & 45 & 49 & 1 & 19 & 20 & 1 & 14 & 15 & 181 \\
\hline 5 & Serpong & 21 & 38 & 59 & 4 & 38 & 42 & 2 & 23 & 25 & 2 & 10 & 12 & 138 \\
\hline 6 & $\begin{array}{l}\text { Serpong } \\
\text { Utara }\end{array}$ & 16 & 17 & 33 & 2 & 16 & 18 & 1 & 6 & 7 & 1 & 2 & 3 & 61 \\
\hline 7 & Setu & 12 & 7 & 19 & 2 & 10 & 12 & 2 & 3 & 5 & 1 & 4 & 5 & 41 \\
\hline
\end{tabular}

Sumber : Data Refrensi KEMENDIKBUD 2016 
Sekolah Dasar Al-Syukro Universal merupakan salah satu lembaga pendidikan swasta yang berdiri di kawasan kecamatan Ciputat Tangerang Selatan yang berlokasi di Jl. Otista Raya Gg. H. Maung No.30. Guru-guru Perguruan Islam AI Syukro Universal merupakan pengajar profesional yang pada umumnya bergelar strata satu dan magister sebanyak dua orang. Mereka secara terpilih dan secara terus menerus dibina dengan berbagai pelatihan dan pengembangan keterampilan. Sekolah Islam Al-Syukro universal yang telah berdiri di tahun 2003 terus mengalami perkembangan hingga di tahun 2011 mendapat akreditasi "A" dari Dinas Pendidikan setempat. Hal ini semakin menunjukan kompetensi sekolah Al-Syukro Universal sebagai layanan jasa pendidikan yang berkualitas apalagi dengan di dukung dengan muatan kurikulum SD Islam Al-syukro Universal yang terdiri dari:

1. Kurikulum Diknas

2. Muatan Kekhasan Al-Syukro

Dengan mengacu pada visi SD Al-Syukro Universal yang berbasis keislaman, kekhasan Al-Syukro yang sekaligus menjadi keunggulan AlSyukro adalah:

a. Bilingual Program

b. Kegiatan Keagamaan

Tahsin

Tahfiz

Dhuha, Dhuhur dan Ashar berjamaah

c. TIK

d. Kegiatan Pengembangan Diri

Tabel 2. Penerimaan Siswa Baru Tahun Ajaran 2011 - 2017

\begin{tabular}{|c|c|c|}
\hline Tahun Ajaran & Jumlah & Persentase (\%) \\
\hline \hline $2016 / 2017$ & 80 & $12,26 \%$ \\
\hline $2015 / 2016$ & 133 & $20,39 \%$ \\
\hline $2014 / 2015$ & 160 & $24,53 \%$ \\
\hline $2013 / 2014$ & 123 & $18,86 \%$ \\
\hline $2012 / 2013$ & 99 & $15,18 \%$ \\
\hline $2011 / 2012$ & 57 & $8,73 \%$ \\
\hline Jumlah & $\mathbf{6 5 2}$ & $\mathbf{1 0 0} \%$ \\
\hline
\end{tabular}

Sumber: PSB SD Al-Syukro Universal

\section{B. Perumusan Masalah}


Berpangkal dari latar belakang masalah seperti yang telah diuraikan diatas,

Perumusan masalah sebagai berikut :

1. Bagaimana kondisi daya saing SD Islam Al-Syukro saat ini?

2. Bagaiman strategi peningkatan daya saing Sd Islam Al-Syukro dalam menghadapi penguatan daya saing di tahun 2017?

\section{Tujuan Penelitian}

1. Menganalisis kondisi daya saing SD Islam Al-Syukro saat ini.

2. Menganalisi strategi peningkatan daya saing SD Islam Al-Syukro yang lebih tepat agar mampu mengimbangi penguatan daya saing di tahun 2017.

\section{Metodologi}

Data yang telah di peroleh kemudian dianalisis dengan menggunakan metode deskriptif dengan menggunakan alat bantu analisis. Tujuan metode deskriptif adalah untuk membantu memberikan gambaran secara sistematis, actual dan akurat mengenai fakta-fakta, sifat, sertahubungan antara fenomena yang diteliti. Analisis kualitatif digunakan untuk lingkungan perusahaan terkait dengan kekuatan, kelemahan, peluang dan ancaman yang dihadapi perusahaan. Alat analisis yang akan digunakan dalam penelitian ini adalah sebagai berikut:

\section{Matrik Eksternal Factor Evaluation}

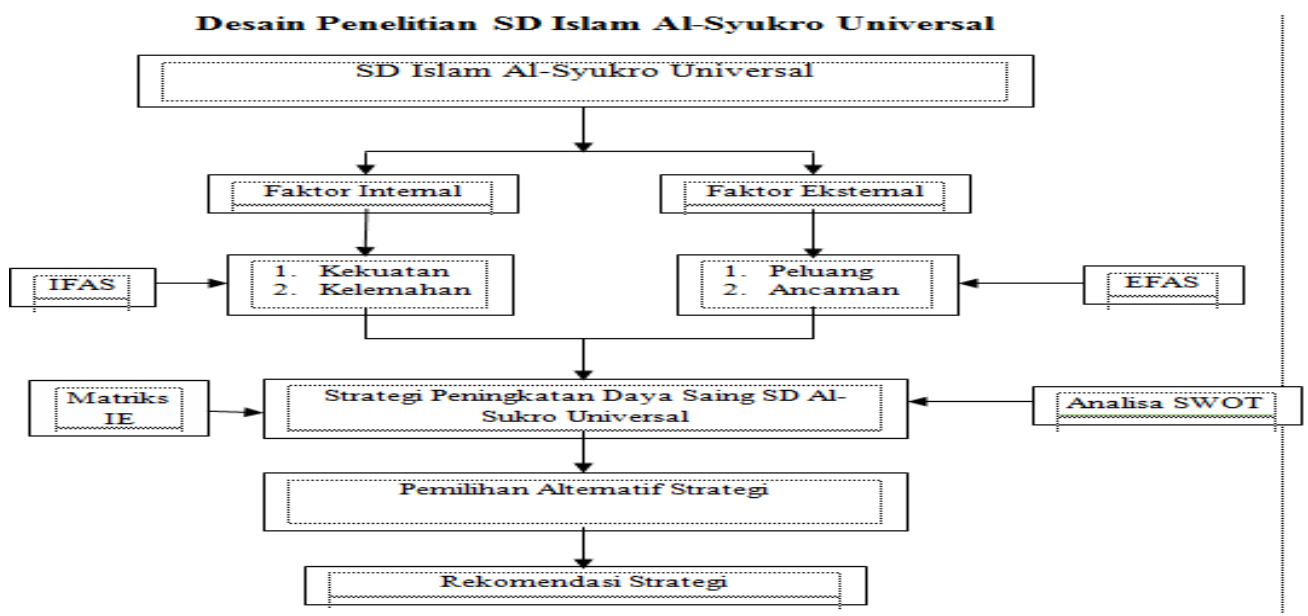

Diagram 1. Matrik EFE

\section{E. Hasil dan Pembahasan}


a. Posisi Kondisi Daya Saing SD AI-Syukro Universal

1) Skoring Data Rekapitulasi IFAS

\begin{tabular}{|c|c|c|c|c|}
\hline $\begin{array}{l}N \\
0\end{array}$ & Lingkungan Internal & $\begin{array}{c}\text { Bobo } \\
t\end{array}$ & $\begin{array}{l}\text { Ratin } \\
g\end{array}$ & $\begin{array}{c}\text { Nila } \\
\text { i }\end{array}$ \\
\hline & Kekuatan & & & \\
\hline 1 & $\begin{array}{l}\text { Akreditasi dan prestasi kejuaraan sekolah menjadi } \\
\text { daya tarik konsumen }\end{array}$ & 0,30 & 3,5 & $\begin{array}{c}1,0 \\
5\end{array}$ \\
\hline 2 & $\begin{array}{l}\text { Lingkungan SD Al-Syukro yang luas, asri, rindang } \\
\text { dan aman }\end{array}$ & 0,25 & 3,4 & $\begin{array}{c}0,8 \\
5\end{array}$ \\
\hline 3 & Bilingual program & 0,35 & 3,8 & $\begin{array}{c}1,3 \\
3\end{array}$ \\
\hline 4 & Ketersediaan anggaran untuk aktivitas pendidikan & 0,10 & 3,1 & $\begin{array}{c}0,3 \\
1\end{array}$ \\
\hline \multicolumn{2}{|r|}{ Sub total 1} & 1 & & $\begin{array}{c}3,5 \\
4\end{array}$ \\
\hline \multirow[b]{2}{*}{1} & Kelemahan & & & \\
\hline & $\begin{array}{l}\text { Kecukupan dan kualitas guru dan SDM belum } \\
\text { maksimal }\end{array}$ & $-0,30$ & 2,2 & $\begin{array}{c}- \\
0,6 \\
6\end{array}$ \\
\hline 2 & $\begin{array}{l}\text { Sistem pendidikan belum terarah dan terukur } \\
\text { sehingga terjadi perubahan tiap tahun }\end{array}$ & $-0,35$ & 2,7 & $\begin{array}{c}- \\
0,9 \\
5\end{array}$ \\
\hline 3 & $\begin{array}{l}\text { Kegiatan promosi dan pemasaran belum } \\
\text { maksimal }\end{array}$ & $-0,25$ & 1,8 & $\begin{array}{c}- \\
0,4 \\
5\end{array}$ \\
\hline \multirow[t]{2}{*}{4} & \multirow[t]{3}{*}{ Fasilitas belum termaintenance dengan baik } & $-0,10$ & 1,7 & $\begin{array}{c}- \\
0,1 \\
7\end{array}$ \\
\hline & & -1 & & $\begin{array}{c}2,2 \\
3\end{array}$ \\
\hline & & & 1,31 & \\
\hline
\end{tabular}

Sumber: Data Primer diolah (2017) 
2) Skoring Data Rekapitulasi EFAS

\begin{tabular}{|c|c|c|c|c|}
\hline No & Lingkungan Eksternal & Bobot & Rating & Nilai \\
\hline & Peluang & & & \\
\hline 1 & $\begin{array}{l}\text { Letak geografis yang memudahkan akses lokasi dan } \\
\text { transportasi. }\end{array}$ & 0,30 & 3,7 & 1,11 \\
\hline 2 & $\begin{array}{l}\text { Pemanfaatan teknologi terhadap akses, kinerja, dan } \\
\text { proses di Alsyukro }\end{array}$ & 0,25 & 3,5 & 0,88 \\
\hline 3 & $\begin{array}{l}\text { Sekolah Al-Syukro Universal menjadi bagian dari } \\
\text { dompet dhuafa republika yang merupakan lembaga } \\
\text { pengelola wakaf \& zakat ternama. }\end{array}$ & 0,35 & 3,8 & 1,33 \\
\hline 4 & $\begin{array}{l}\text { Dukungan dan support pemkot Tangsel pada } \\
\text { Pendidikan }\end{array}$ & 0,10 & 3,4 & 0,34 \\
\hline \multicolumn{2}{|c|}{ Sub total 1} & 1 & & 3,66 \\
\hline \multirow[b]{2}{*}{1} & \multicolumn{4}{|l|}{ Ancaman } \\
\hline & Perkembangan mutu sekolah pesaing & $-0,30$ & 2,4 & $-0,72$ \\
\hline 2 & Perkembangan program pemasaran sekolah pesaing & $-0,25$ & 2,5 & $-0,53$ \\
\hline 3 & Minat orang tua dalam mendaftar di Al-Syukro & $-0,35$ & 2,1 & $-0,88$ \\
\hline 4 & Ketepatan waktu dalam pembayaran biaya sekolah & $-0,10$ & 1,8 & $-0,18$ \\
\hline \multicolumn{2}{|r|}{ Sub total 2} & -1 & & $-2,31$ \\
\hline & Graand Total & \multicolumn{3}{|c|}{1,35} \\
\hline
\end{tabular}

Sumber: Data Primer diolah (2017)

Berdasarkan hasil skoring, pada 7 responden (Manajer keuangan, Kepala sekolah, Bagian Kesiswaan, Bagian Kurikulum, Guru dan 2 orang Wali Murid) dapat diketahui analisis IFAS dan EFAS sebagai berikut:

1. Lingkungan Internal

a. Faktor Kekuatan

Berdasarkan hasil skoring analisa, dapat diketahui bahwa aspek internal untuk indikator kekuatan (strength) yaitu mendapatkan total skor sebesar 3,54 dengan rincian terdiri dari beberapa indikator yaitu akreditasi dan prestasi kejuaraan sekolah $(1,05)$, lingkungan sekolah yang asri, luas, rindang dan aman $(0,85)$, bilingual program $(1,33)$, ketersediaan anggaran 
pendidikan (0,31).Dalam hal aspek internal untuk indikator kekuatan (strength) dengan nilai sub total 3,54 didapatkan dua urutan besar yaitu (1) bilingual program dengan nilai 1,33 menunjukan bahwa sekitar 38\% indikator bilingual program berperan sangat penting pada peningkatan daya saing sekolah. (2) akreditasi A dan prestasi kejuaraan sekolah dengan nilai 1,11 menunjukan bahwa sekitar 31\% unsur akreditasi dan prestasi kejuaraan sekolah dipersepsikan sebagai daya pendorong pertumbuhan kemajuan sekolah. Dua aspek tersebut menjadi dominan kekuatan, artinya kedua aspek tersebut sangat mempengaruhi peningkatan daya saing di SD Al-Syukro Universal.

b. Faktor Kelemahan

Berdasarkan hasil skoring, dapat diketahui bahwa aspek internal untuk indikator kelemahan (weakness) yaitu mendapatkan total skor sebesar 2,23 dengan rincian terdiri dari beberapa indikator yaitu kecukupan dan kualitas guru dan SDM yang belum maksimal $(-0,66)$, sistem pendidikan yang belum terarah dan terukur $(-0,95)$, kegiatan promosi dan pemasaran belum maksimal $(-0,45)$, fasilitas belum termentenance dengan baik $(-0,17)$.

Dalam hal aspek internal untuk indikator kelemahan (weakness) dengan nilai subtotal -2,23 didapatkan dua urutan besar yaitu (1) sistem pendidikan yang belum terarah dan terukur dengan nilai -0,95 menunjukan bahwa sekitar 43\% unsur sistem pendidikan yang belum terarah dan terukur dipersepsikan sebagai variabel yang sangat berpengaruh, hal ini berkenaan dengan pertumbuahan jumlah siswa setiap tahunnya. (2) kecukupan dan kualitas guru dan SDM belum maksimal dengan nilai -0,66 menunjukan $30 \%$ unsur kecukupan dan kualitas guru dan SDM yang belum maksimal menjadi penghambat aktivitas pertumbuhan lembaga pendidikan Al-Syukro Universal.

\section{Lingkungan Eksternal}

a. Faktor Peluang

Berdasarkan hasil skoring analisa SWOT, dapat diketahui bahwa aspek eksternal untuk indikator peluang (opportunity)yaitu mendapatkan total skor sebesar 3,66 dengan rincian terdiri dari beberapa indikator yaitu letak geografis yang memudahkan akses lokasi dan transportasi $(1,11)$, pemanfaatan teknologi terhadap akses, kinerja, dan proses di Alsyukro 
$(0,88)$, sekolah Al-Syukro Universal menjadi bagian dari dompet dhuafa republika yang merupakan lembaga pengelola wakaf \& zakat ternama $(1,33)$, dukungan dan support PemKot Tangsel pada pendidikan $(0,34)$.

Dalam hal aspek ekternal untuk indikator peluang (opportunity) dengan sub total 3,66 didapatkan dua urutan besar yaitu (1) Al-syukro menjadi bagian dari dompet dhuafa republika yang merupakan pengelola wakaf \& zakat ternama dengan nilai 1,33 menunjukan 36\% unsur Al-syukro menjadi bagian dari dompet dhuafa republika yang merupakan pengelola wakaf \& zakat ternama dapat diperkirakan menjadi potensi peningkatan daya saing di SD Al-Syukro Universal. (2) letak geografis yang memudahkan akses lokasi dan transportasi dengan niali 1,11 menunjukan $30 \%$ unsur letak geografis yang memudahkan akses lokasi dan transportasi dapat menjadi potensi untuk dapat menarik konsumen dalam upaya peningkatan daya saing lembaga terhadap kompetitornya.

b. Faktor Ancaman

Berdasarkan hasil skoring analisis, dapat diketahui bahwa aspek eksternal untuk indikator ancaman (threat)yaitu mendapatkan total skor sebesar -2,31 dengan rincian terdiri dari beberapa indikator yaitu meningkatnya jumlah sekolah pesaing $(-0,72)$, perkembangan mutu sekolah pesaing $(-0,53)$, Minat orang tua dalam mendaftar di Al-Syukro ($0,88)$, Ketepatan waktu dalam pembayaran biaya sekolah $(-0,18)$.

Dalam hal aspek ekternal untuk indikator ancaman dengan sub total 2,31 didapatkan dua urutan besar yaitu (1) Minat orang tua dalam mendaftar di Al-Syukro dengan nilai -0,88 menunjukan 26\% unsur minat orang tua mempengaruhi pemilihan sekolah SD yang berdampak besar bagi pertumbuhan SD Islam Al-Syukro Universal. (2) indikator perkembangan mutu sekolah pesaing yaitu $-0,72$ menunjukan keduanya sebesar 31\% mempengaruhi tingkat ancaman bagi peningkatan daya saing di SD AI-Syukro Universal.

Maka dari analisis di atas, dari aspek internal (IFAS) dengan rincian yaitu indikator kekuatan (strength) sebesar 3,54 dikurangi dengan indikator kelemahan (weakness) yaitu -2,23 menghasilkan grand total sebesar 1,31. Dan hasil dari aspek eksternal (EFAS) dengan rincian yaitu indikator peluang (opportunity) sebesar 3,66 dikurangi dengan indikator ancaman 
(threath) yaitu $-2,31$ menghasilkan nilai grand total sebesar 1,35. Nilai total skor faktor analisiss internal SD Islam AI-Syukro Universal adalah sebesar 1.31, sedangkan nilai total skor atas faktor-faktor analisis eksternal adalah sebesar 1.35. Hal ini dapat diartikan bahwa faktor analisis eksternal memiliki pengaruh yang lebih besar dibandingkan dengan faktor analisiss internal.

Dari analisis yang telah di jabarkan di atas, dapat di gambarkan kondisi strategis SD AI-Syukro Universal dalam sebuah grafik sesuai di bawah ini

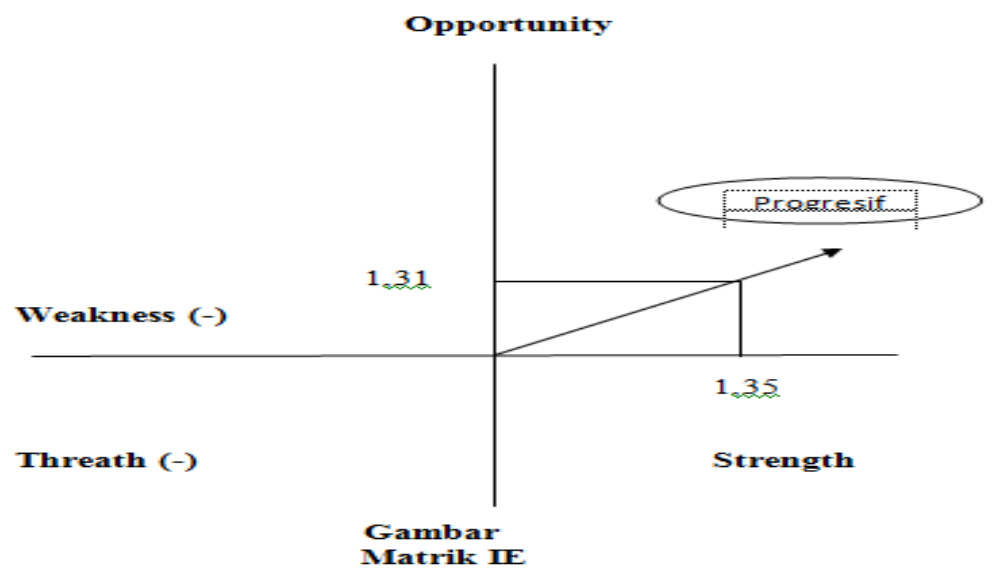

Berdasarkan matrik IE dapat dilihat bahwa SD AI-Syukro berada pada sel I (kuadran I) yaitu Progresif $\mathrm{Hal}$ ini menunjukan bahwa perusahaan tersebut berada pada kondisi sangat bagus untuk memanfaatkan kekuatan internalnya untuk (1) menarik keuntungan dari peluang eksternal, (2) mengatasi kelemahan internal dan (3) menghindari beragam ancaman eksternal. Analisis yang paling baik adalah analisis Grow and Build (Tumbuh dan Berkembang). Analisis-analisis yang umumnya digunakan adalah analisis intensif seperti menjalankan ekspansi, memperbesar pertumbuhanmarket penetration, market development dan product development. Maka untuk selanjutnya dapat dipergunakan metode analisis SWOT dalam menentukan strategi pengkatan daya saing SD Al-Syukro Universal. 


\begin{tabular}{|c|c|c|}
\hline \multicolumn{3}{|c|}{ Analisis Matrik SWOT SD Al-Syukro Universal } \\
\hline \multirow{5}{*}{ SWOT } & STRENGTH & WEAKNESS \\
\hline & $\begin{array}{l}\text { a. Akreditasi dan prestasikejuara an yang di raih } \\
\text { sekolahmenjadi daya tarik konsumen }\end{array}$ & $\begin{array}{l}\text { a. Kecukupan dankualitas guru dan SDM } \\
\text { belum maksimal }\end{array}$ \\
\hline & $\begin{array}{l}\text { b. Lingkungan sekolah SD Al-Syukro yang } \\
\text { luas, asri, indang dan aman bagipeserta didik }\end{array}$ & $\begin{array}{l}\text { b. System pendidikan belum terarah dan } \\
\text { terukur sehingga terja diperubahan tiap } \\
\text { tahun }\end{array}$ \\
\hline & $\begin{array}{l}\text { c. Bilingual program menja di keunggulanpada } \\
\text { program pada pembelajaran dan aktifitaskelas }\end{array}$ & $\begin{array}{l}\text { c. Kegiatan promosi danpemasaran belum } \\
\text { maksimal }\end{array}$ \\
\hline & $\begin{array}{l}\text { d. Ketersediaan anggaran untuk ahtivitas } \\
\text { pendidikan }\end{array}$ & $\begin{array}{l}\text { d. Fasilitas belum temaintenance dengan } \\
\text { baik }\end{array}$ \\
\hline OPPORTUNITIES & Strategi SO & Strategi WO \\
\hline $\begin{array}{l}\text { a. Letak geografis yang memudahkan akses } \\
\text { lokasi dan transportasi }\end{array}$ & $\begin{array}{l}\text { 1. Mengoptimalkan program pemasaran secara } \\
\text { langsung dantidaklangsung }\end{array}$ & $\begin{array}{l}\text { 1. Mengkajikuantitas dan danmeningkatkan } \\
\text { kualitas SDMlembaga }\end{array}$ \\
\hline $\begin{array}{l}\text { b. Pemanfa atan teknologiterhadap akses, } \\
\text { kinerja, dan proses di Al-Syukro }\end{array}$ & 2. Menjaga kualitas programpendidikan & $\begin{array}{l}\text { 2. Perbaikan system pendidikan dengan } \\
\text { melibatkan relasi dan pemerintah }\end{array}$ \\
\hline c. Sekolah Al-Syukro Universal meniadi & 3. Memanfa atkan jaringannetworking dalam & 3. Memaksimalkan tehnolog sebagai sarana \\
\hline $\begin{array}{l}\text { bagian dari dompet dhuafa republika yang } \\
\text { merupakan lembaga pengelola wakaf } \\
\text { \&zakat temama. }\end{array}$ & pemasaran & promosi dan pemasaran \\
\hline $\begin{array}{l}\text { d. Dukungan dan support pemkot Tangsel } \\
\text { pada pendidikan }\end{array}$ & $\begin{array}{l}\text { 4. Berperan aktif dalamkeikutsertaansekolah di } \\
\text { dinaspendidikan }\end{array}$ & $\begin{array}{l}\text { 4. Adanya pengawasan danproses } \\
\text { maintenance yangkontinue }\end{array}$ \\
\hline THREATS & Strategi ST & Strategi WT \\
\hline a. Perkembangan mutu sekolah pesaing & 1. Melakukan gerilya promosi dan pemasaran & $\begin{array}{l}\text { 1. Menerapkan keseragaman konsep } \\
\text { pendidikan dalam aspek perencanaan, } \\
\text { pengelolaan, evaluasi, hingga model } \\
\text { pengembangan sekolah dan } \\
\text { pembelajaran }\end{array}$ \\
\hline $\begin{array}{l}\text { b. Perkembangan program pemasarn } \\
\text { sekolah pesain }\end{array}$ & $\begin{array}{l}\text { 2. Melakukan studi banding dan riset } \\
\text { perbaikan lembaga }\end{array}$ & $\begin{array}{l}\text { 2. Menjalin hubungan baik dengan } \\
\text { lingkungan }\end{array}$ \\
\hline $\begin{array}{l}\text { c. Minat orang tua dalam mendaftar di } \\
\text { Al-Syukro }\end{array}$ & $\begin{array}{l}\text { 3. Menciptakan citra positif lembaga di } \\
\text { benak masyarakat }\end{array}$ & $\begin{array}{l}\text { 3. Meningkatkan fasilitas sarana } \\
\text { pendidikan }\end{array}$ \\
\hline $\begin{array}{l}\text { d. Ketepatan waktu dalam pembayaran } \\
\text { biaya sekolah }\end{array}$ & $\begin{array}{l}\text { 4. Memaksimalkan penggunaan anggaran } \\
\text { pendidikan }\end{array}$ & $\begin{array}{l}\text { 4. Memanfaatkan teknologi untuk } \\
\text { peningkatan pelayanan pada proses } \\
\text { pembayaran biaya pendidikan }\end{array}$ \\
\hline
\end{tabular}

\section{Pembahasan}




\section{Kondisi Strategi SD AI-Syukro Universal Saat Ini}

Kondisi strategi yang dijalankan oleh SD AI-Syukro Universal saat ini adalah :

a) Kondisi strategi yang menunjukan Strength (S) yakni, situasi kondisi yang merupakan kekuatan dari organisasi atau program pada saat ini:

1) Akreditasi A dan prestasi kejuaraan yang di raih sekolah menjadi daya tarik konsumen

Akreditasi yang dimiliki AL-syukro adalah "A".Akreditasi dan prestasi sekolah merupakan salah satu daya tarik utama para orang tua memasukan putra-putrinya ke sebuah lembaga pendidikan.Selain akreditasi, prestasi dan kualitas sekolah juga dapat terlihat dari hasil kejuaraan yang di raihnya.

2) Lingkungan sekolah SD Al-Syukro yang luas, asri, rindang dan aman bagi peserta didik.

Sekolah Al-Syukro Universal yang berdiri di area seluas 2,75 $\mathrm{Ha}$, menjadikan lingkungan pendidikan ini nampak luas. Berbagai area fasilitas seperti dua buah lapangan sepak bola, lapangan basket, area berkebun siswa, kantin dan gedung terbangun dengan area yang cukup luas.Keadaan lingkungan yang banyak tertanam pohon rindang yang banyak membuat suasana sekolah sejuk kondisi ini sangatlah baik bagi peserta didik khususnya dengan kondisi udara yang terkena polusi di wilayah ciputat akibat kuantitas jumlah kendaraan.

3) Bilingual program menjadi keunggulan pada program pada pembelajaran dan aktifitas kelas

Merupakan program inovasi pembelajaran yang membina ketrampilan berbahasa dan berkomunikasi dengan bahasa inggris secara lisan dan tertulis untuk menghadapi perkembangan ilmu pengetahuan dan teknologi yang terdapat pada muatan pelajaran.Perkembangan era globalisasi menuntut untuk seseorang mampu menyesuaikan dengan keadaaan dan kebutuhan zaman. Kemampuan bahasa menjadi salah satu kemampuan yang dapat memenuhi kebutuhan dan tantangan di era modern dan globalisasi sehingga inovasi dan fokus pada sistem pembelajaran ini menjadi nilai penting bagi peningkatan mutu pendidikan.

4) Ketersediaan anggaran untuk aktivitas pendidikan 
Ketersediaan dana pendidikan menjadi prioritas dalam upaya keberlangsungan kegiatan pendidikan. SD Al-Syukro universal yang bernaung di bawah yayasan Al-syukro Universal memiliki kapasitas dalam mengatur dan mengakomodasi dana pendidikan. Perhatian pemerintah akan keberlangsungan pendidikan juga menjadi salah satu pendorong dalam keberlangsungan aktivitas pendidikan. Oleh karenanya lewat bantuan alokasi pendidikan dari pemerintah itulah diharapkan sekolah mampu memberikan pelayanan pendidikan terbaik bagi peserta didik.

b) Kondisi SD Al-Syukro yang menunjukan Weakness (W), yaitu situasi atau kondisi yang merupakan kelemahan dari organisasi atau program saat ini

\section{1) Kecukupan dan kualitas guru dan SDM belum maksimal}

Pemerataan ketersediaan SDM di lembaga pendidikan AI-Syukro universal masih belum berjalan maksimal hal ini disebabkan masih ada beberapa guru yang memiliki kelebihan jam mengajar. Pemerataan kuantitas SDM di beberapa lini masi belum terjadi sehingga seringkali menghambat aktivitas proses di Al-Syukro Universal.Kualitas dan keterbatasan guru pada program bilingual dan tahfiz dalam proses pengajaran mengakibatkan guru-guru yang berlatar belakang sosial pada akhirnya diharuskan untuk mengampu mata pelajaran tahfiz dan bilingual sebagai alternatif berjalannya program sekolah.

2) Sistem pendidikan belum terarah dan terukur sehingga terjadi perubahan tiap tahun.

Beberapa perubahan sistem pendidikan yang terjadi di SD AI-Syukro diantaranya adalah perubahan jam masuk siswa menjadi 7.45 untuk peserta didik baru. Hal itu mengakibatkan pemangkasan pada beberapa program pendidikan yang sudah berjalan di tahun sebelumnya seperti jumat bersih, spelling day, Al-Sky Uni fest, dan Spelling day. Inovasi program melalui program bilingual tidak di dukung oleh adanya buku pedoman sebagai acuan pembelajaran.

\section{3) Kegiatan promosi dan pemasaran belum maksimal}

Aktifitas kegiatan promosi dan pemasaran di Al-Syukro kurang berjalan maksimal, seperti kurang aktifnya pemasaran di media online, dan masih berfokus pada penyebaran brosur di beberapa sekolah tertentu. 


\section{4) Fasilitas belum termaintenance dengan baik}

Beberapa fasilitas di Al-Syukro masih belum termentenance dengan baik seperti masih adanya ruang kelas yang bocor ketikahujan, keadaan toilet siswa yang kotor dan tak dapat difungsikan, AC kelas yang tidak berasa dingin karena jarang di servis.

c) Kondisi SD AI-Syukro yang menunjukan Oportunity $(\mathrm{O})$, yaitu situasi atau kondisi yang merupakan peluang di luar organisasi dan memberikan peluang berkembang bagi organisasi.

1) Letak geografis yang memudahkan akses lokasi dantransportasi.

Letak SD Al-Syukro yang berada di area pamulang dan ciputat menjadi sebuah tempat strategis.Lokasinya yang berada dekat dengan jalan raya memudahkan untuk di kunjungi dan dapat menjadi nilai positif lembaga.

2) Pemanfaatan teknologi terhadap akses, kinerja, dan proses di AlSyukro

Aktifitas kegiatan dan proses di SD Al-syukro universal sudah menggunakan media elektronik seperti komputer, infokus, telepon, dan internet. Hal ini membantu mempercepat akses kinerja di SD Al-Syukro Universal.

3) Sekolah Al-Syukro Universal menjadi bagian dari dompet dhuafa republika

Di tahun 2010 sekolah Al-syukro menjadi bagian dari dompet dhuafa republika yang merupakan lembaga pengelola waqaf dan zakat ternama. Dengan adanya koordinasi bersama akan dapat membawa peluang dan dampak bagi peningkatandaya saing lembaga.

4) Dukungandan support pemkot Tangsel pada pendidikan

Pemerintah kota tangerang selatan melalui dinas pendidikan memberikan dukungan pendidikan dalam bentuk pengalokasian dana pendidikan kepada sekolah negeri maupun swasta setingkat SD sampai dengan SMP. Melalui pemberian dana pendidikan tersebut lembaga AlSyukro memiliki dana tambahan di luar dana yayasan dalam menjalankan aktivitas pembelajaran siswa. 
d) Kondisi SD Al-Syukro Universal yang menunjukan Threat $(T)$ yaitu situasi yang merupakan ancaman bagi organisasi yang datang dari luar organisasi dan dapat mengancam eksistensi organisasi

1) Perkembangan mutu sekolah pesaing

2) Perkembangan program pemasaran sekolah pesaing

3) Minat orang tua dalam mendaftar di Al-Syukro

4) Ketepatan waktu dalam pembayaran biaya sekolah

\section{Strategi Yang Dapat Dijalankan SD AI-Syukro Universal}

\section{a. Analisa Strategi S-O (Strength-Opportunity)}

Posisi dari daya saing berdasarkan analisis SWOT berada pada posisi SO (Strength Opportunity) merupakan strategi yang mengutamakan kekuatan dan memanfaatkan peluang yang ada.Strategi ini dapat digunakan untuk mendukung kebijakan pertumbuhan yang agresif.Beberapa inovasi aktifitas perlu dilakukan dan diupayakan oleh seluruh sumber daya manusia di Al-Syukro Universal.

Mengoptimalkan program pemasaran secara langsung dan tidak langsung.Pemasaran dan pengenalan produk pendidikan menjadi hal yag sangat penting bagi lembaga pendidikan. Melalui pemasaran masyarakat akan mengetahui produk, mutu maupun keunggulan dari sebuah lembaga Beberapa upaya yang dapat dilakukan dalam program pemasaran langsung dan tidak langsung adalah pemasangan baleho promosi sekolah di tempat strategis, kanvasing pemasaran di TK terdekat, mengaktifkan kembali dalam pemasaran lewat media online yang sudah ada sebelumnya.

Mengoptimalkan jaringan networking dalam pemasaran.Jaringan networking yang berasal baik dari dompet dhuafa sebagai vendor, maupun ynag berasal dari pemerintah dan orang tua siswa hendaknya dapat di manfaatkan secara maksimal agar membuka dan mempermudah peluang yang dapat meningktkan daya saing sekolah. Adapun upaya yang dapat dilakukan seperti folloup data networking, embuka stand bazar pemasaran di tiap event kegiatan dompet dhuafa republika, Melakukan kegiatan bersama atau mandiri dengan lembaga dompet dhuafa republika yang bertempat di SD AI-Syukro Universal. 
Berperan aktif dalam keikutsertaan sekolah pada kegiatan dinas pendidikan. Sekolah al-syukro yang berada di bawah naungan dinas pendidikan sangat penting dalam membina hubungan baik pemerintah. Berbagai informasi terkait pendidikan akan dapat tersampaikan dengan adanya komunikasi dan kesetaan lembaga pendidikan dengan pemerintah baik dalam bentuk aktif menghadiri pertemuan di tingkat gugus sekolah wilayah ciputat atau ikut serta dalam kegiatan dinas pendidikan dalam bentu pelatihan, sosialisasi, workshop, bimtek dll. Selain itu juga untuk mempertahankan dan memperkuat posisi Strength Opportunity perlu diikuti oleh analisis strategi-strategi ST, WO dan WT, yakni sebagai berikut:

\section{b. Analisis strategi ST (Strength-Threat)}

Analisis strategi ST (Strenght Threats) merupakan strategi dengan memanfaatkan kekuatan untuk mengatasi tantangan yang ada,Hal ini dapat dilakukan dengan beberapa strategi.

Melakukan gerilya promosi dan pemasaran.Strategi penawaran kepada market share di wilayh kompetitor adalah cara lain untuk bisa memperluas market dan peningkatan daya saing mengingat beberapa keunggulanyang dimiliki. Upaya yang dapat dilakukan seperti mengunjungi TK-Tk dalam upaya pemasaran sekolah, melakukan strat pemasaran di akhir semester 1 pendidikan guna mengoptimalkan input pendafrtaran siswa baru, mengadakan kegiatan yang diikuti oleh TK di wilayah ciputat dan sekitarnya, mengoptimalkan program diskon pendaftaran siswa baru.

Melakukan studi banding dan riset perbaikan lembaga.Studi banding merupakan sebagai upaya pengembangan yang dipandang perlu diperhatikan dalam upaya peningkatan daya saing.

Menumbuhkan citra positif lembaga di benak masyarakat.Kesan danpandangan positif terhadap suatu lembaga akan mampu meningkatkan daya saing. Citra positif mampu sebagai pemasaran berjalan, hal ini kareana orang-orang yang memiliki kesan positif di luar lembaga akan bercerita dan secara tidak langsung membawa word of mouth positif di masyarakat.

\section{c. Analisis Strategi WO (Weakness-Opportunity)}


Analisis strategi WO (weakness Opportunity) merupakan strategi yang meminimalkan kelemahan intern untuk dapat bertahan (defensive) dalam menghadapi tantangan.Hal ini dapat dilakukan dengan beberapa strategi.

Mengkaji kuantitas dan meningkatkan kualitas SDM lembaga.Sumber daya manusia merupakan elemen terpenting dalam sebuah proses. Baik kualitas maupun kesesuaian jumlah SDM pada tiap lini perlu mendapat perhatian sehingga tidak terjadi penumpukan aktivitas pada lini-lini tertentu yang dapat mengganggu aktivitas lembaga. Adapun upaya yang dapat dilakukan dalam peningkatan SDM di SD Al-Syukro adalah menempatkan SDM sesuai dengan bakat dan ketrampilannya, mengadakan pelatihan peningkatan kualitas SDM di semua lini lembaga, menempatkan jumlah SDM di tiap lini sesuai dengan kebutuhan lini lembaga, perekrutan SDM baru yg berkualitas sesuai dengan kebutuhan,

Perbaikan sistem pendidikan dengan melibatkan relasi dan pemerintah.Perbaikan sistem yang melibatkan relasi sumber daya manusia yang ada khususnya dari dompet dhuafa republika yang memiliki kompetensi dalam pendidikan akan dapat meningkatkan perbaikan di SD Al-Syukro Universal.

Memaksimalkan tehnologi sebagai sarana promosi dan pemasaran.Ketersediaan fasilitas tehnologi seperti telefon, internet, email, sosial media dan lainnya akan lebih bernilai guna jika dimanfaatkan secara optimal sehingga perlu adanya pengaktifan kembali pemasaran jejaring sosial dengan cara mengupload setiap aktivitas dan kegiatan pendidikan di medsos yang ada (FB, IG, Youtube) sehingga dapat meningkatkan peningkatan daya saing di SD AI-Syukro Universal.

Adanya pengawasan dan proses maintenance yang kontinue.

\section{d. Analisis Strategi WT (Weakness-Threath)}

Analisis strategi WT (weakness Threats) merupakan strategi yang meminimalkan kelemahan intern untuk dapat bertahana (defensive) dalam menghadapi tantangan.Hal ini dapat dilakukan dengan beberapa strategi. 
Menerapkan keseragaman konsep pendidikan dalam aspek perencanaan, pengelolaan, evaluasi, hingga model pengembangan sekolah dan pembelajaran.

Menjalin hubungan baik dengan lingkungan.Hubungan yang baik yang tercipta dari hubungan positif lembaga dengan lingkungan eksternal akan dapat menciptakan citra positif lembaga.Hubungan baik tersebut dapat terjadi melalui komunikasi anatara lembaga dengan lingkungan eksternal maupun aktifitas antara lembaga yang melibatkan lingkungan atau masyarakat seperti pemberian bantuan sosial, perbaikan jalan di area menuju sekolah dll.

Meningkatkan fasilitas sarana pendidikan.

Memanfaatkan teknologi untuk peningkatan pelayanan pada proses pembayaran biaya pendidikan.

\section{G. Kesimpulan}

Berdasarkan uraian dari hasil analisis serta pembahasan mengenai strategi bersaing SD Al-Syukro Universal maka dapat simpulkan sebagai berikut:

1. Pada kondisi lingkungan internal internal (IFAS) dengan rincian yaitu indikator kekuatan (strength) sebesar 3,54 dikurangi dengan indikator kelemahan (weakness) yaitu -2,23 menjadi grand total sebesar 1,31 bernilai posistif. Pada aspek eksternal (EFAS) dengan rincian yaitu indikator peluang (opportunity) sebesar 3,66 dikurangi dengan indikator ancaman (threath) yaitu -2,31 menjadi grand total sebesar 1,35 bernilai positif. Kedua kondisi baik internal maupun ekternal keduanya bernilai positif yang berarti bahwa posisi SD Al-Syukro Universal dalam persaingan bisnisnya berada pada kondisi prospektif (kuadran I ) dari Matrik Kondisi. Hal iniberarti organisasi berada pada posisi yang baik untuk menggunakan kekuatan internalnya guna memanfaatkan peluang eksternal, mengatasi kelemahan internal, dan menghindari ancaman eksternal.

2. Hasil dari skoring analisa SWOT menggambarkan bahwa posisi perusahaan berada pada kuadran I (Prospektif) yang berarti strategi yang dijalankan adalah dengan menggunakan Strategi S-O (StrengthOpportunity) yaitu:

\section{Analisa Strategi S-O (Strength-Opportunity)}


a) Mengoptimalkan program pemasaran secara langsung dan tidak langsung.

Pemasaran dan pengenalan produk menjadi sangat penting guna mengetahui keunggulan sebuah lembaga hal ini dapat dilakukan dengan pemasangan baleho promosi sekolah di tempat strategis, aktif dalam pemasaran media online dan kanvasing.

b) Menjaga kualitas program pendidikan

Kualitas/mutu program bilingual dan keislaman menjadi hal yang amat penting di SD AI-Syukro karena akan mampu meningkatkan skill siswa. Hal ini dapat dilakukan melalui: pelaksanakan kembali program pendidikan yang sudah hilang namun berdampak positif, pembuatan buku acuan pada materi greating dan murojaah, adanya target pencapaian kemampuan bahasa di tiap level, dan membuat inovasi program bilingual dan keislaman.

c) Mengoptimalkan jaringan networking dalam pemasaran

Jaringan networking yang berasal dari dompet dhuafa, pemerintahmaupun orang tua siswa hendaknya dimaksimalkan agar dapat membuka peluang peningkatan daya saing. Hal ini dapat dengan Folloup data networking, membuka stand bazar pemasaran di event kegiatan dompet dhuafa republika, mengadakan kegiatan bersama yang bertempat di SD Al-Syukro Universal.

a) Berperan aktif dalam keikutsertaan sekolah pada kegiatan dinas pendidikanSekolah Al-Syukro yang berada di naungan dinas pendidikan sangat penting dalam membina hubungan baik dengan pemerintah melalui kehadiran di tingkat gugus sekolah wilayah ciputat atau ikut serta dalam kegiatan dinas pendidikan dalam ben meltuk pelatihan, sosialisasi, workshop, bimtek dll.

\section{H. Daftar Pustaka}

Adiatma, Fajar, "Pengaruh Penetapan Harga Produk Terhadap Keputusan Pembelian Konsumen" (Studi Pada Rumah Makan Soto Dan Sop Nanda Jalan Sei Blutu Pasar Ix No.12 Medan), 2013.

Aaker, David A, 2013, Manajemen Pemasaran Strategi, Edisi 8, Jakarta: Salemba

Alma, Buchari dan Hurriyati Ratih. 2008. Manajemen Corporatedan Strategi Pemasaran Jasa Pendidikan Fokus pada Mutu Layanan dan Prima. 
Bandung : CV. Alfabeta Amirullah, 2015, Pengantar Manajemen, edisi 7, Jakarta

Assauri, Sofjan. 2013, ManajemenPemasaran, Jakarta: Rajawali

Baharuddin, dan Moh.Makin, 2010, Pendidikan Humanistik (Konsep, Teori dan Aplikasi Praktis Dalam Pendidikan), HIm 48, Jogjakarta

Bambang Prasetyo dan Lina Miftahul Jannah,2005, Metode Penelitian Kuantitatif Teori dan Aplikasi, Jakarta: PT Raja Grafindo Persada

Basu Swastha dan T. Hani Handoko, 2000, Manajemen Pemasaran, Analisa Perilaku Konsumen. Yogyakarta: BPFE-Yogyakarta

Emzir.2010.Metodologi Penelitian Pendidikan:Kuantitatif dan KualitatifJ akarta: Rajawali Pers.

Engkoswara, dan Komariah, 2010, Administrasi Pendidikan, p 1, Bandung

Esterberg,Kristin G, 2002, Qualitative Methods Ins Social Research,McGraw Hill, New York.

Fahmi, dkk., 2013, Analisis SWOT, Jakarta: Gramedia

Fandi Tjiptono, 2002, StrategiPemasaran, Yogyakarta :Andi

Frans Ghana, 2003, Inovasi Organisasi Sebagai Basis Daya Saing Bisnis, Usahawan.

Freddy, Rangkuti. 2006, Teknik Mengukur dan Strategi Meningkatkan Kepuasan Pelanggan, Jakarta : Gramedia Pustaka Utama

Freddy, Rangkuti, 2013, Buku Analisis SWOT Tehnik Membedah Kasus Bisnis, Jakarta: Gramedia

Fred. R. David, 2013, Stratrgic Management Concepts and Cases, HIm 10-44, Jakarta

Igor Ansoff , 2007, Implanting Strategic Management, Prentice Hall Newyork

Indriantoro, Nur. dan Bambang Supomo. 2002. Metodologi Penelitian Bisnis: Untuk Akuntansi dan Manajemen. Edisi I. Yogyakarta: BPFE

Ismail, Solihin. 2009, Pengantar Manajemen, jilid pertama, Jakarta :Erlangga

Ismail, Solihin, 2012, Pengantar Manajemen, jilid ke dua, Jakarta :Erlangga

Kotler dan Keller, 2000, Manajemen Pemasaran, Edisi Millenium, Jakarta:

Prehallindo

Kotler dan Keller, 2008, Manajemen Pemasaran, Jilid 1, Edisi Ke 13, Jakarta: Erlangga

Muhardi,. 2007.Strategi Operasi Untuk Keunggulan Bersaing.Yogyakarta:Garaha Pustaka.

Oemar Hamalik, 2007, Proses Belajar Mengajar ,P48, Psikologi Pendidikan, Bandung : BumiAksara.

Pearch, dan Robinson, 2013, Manajemen Strategis, Formulasi, Implementasi dan Pengendalian, Jakarta.

Rahayu,2008, StrategiPemasaran Model UntukKeunggulan, HIm 64, Bandung

Ridhotullah, and Jauhar, 2015, PengantarManajemen, Jilid3, Jakarta

Sofyan, 2015, Pintarlnvestasi, Edisi 4, Jakarta

Solihin.and Ismail, 2009, Corporate Social Resposibility From Carity

Sustainability, 4, Jakarta.

Sugiyono, 2001, Metode Penelitian Bisnis, Bandung: Alfabeta 
Sugiyono, 2015, MamahamiPenelitianKualitatif, Bandung: Alfabeta

Sugiyono, 2013, MetodePenelitianPendidikan (PendekatanKuantitatif, Kualitatif, dan $R$ \& D), Bandung: Alfabeta

Suhartanto, Dwi. (2014), MetodeRisetPemasaran, Bandung: Alfabeta

Sunarto, 2004, Prinsip-Prinsip Pemasaran, Jakarta: Gramedia Pustaka Utama

UU RI 1945 pasal 31 ayat 1 Tentang Pendidikan Negara Republik Indonesia

UU RI Nomor 20 Tahun 2003 tentang Sistem Pendidikan Nasional

UU RI Nomor 51 Tahun 2008 tentang Pembentukan Kota Tangerang Selatan

W.F.Glueck, dan L.R.Jauch, 2008, Manajemen Strategi dan Kebijakan Perusahaan

Http:/www.bps.Penduduk Tangerang Selatan, co.id.

Http:/www.kemendikbud.Data Refrensi Kemendikbud, co.id. 